\title{
Propositions in Wittgenstein and Ramsey
}

\author{
Michael Potter \\ University of Cambridge
}

\begin{abstract}
In Begriffsschrift Frege proposed to ignore the part of content that is irrelevant to logic; what remains he called 'conceptual content'. In 'On sense and reference' he renamed this 'sense' but failed to stress that it is a notion belonging to the philosophy of logic, not of language. Russell seems to have seen the importance of the notion only briefly. Wittgenstein did not make use of the notion until he was in Norway, and only introduced the terminology of 'sign' and 'symbol' to mark the distinction while composing the Tractatus. Ramsey proposed to treat sign and symbol as merely two different ways of typing token inscriptions, but this unduly brushes over the difficulties the notion of a symbol involves. The most striking feature of Wittgenstein's thinking on this is the way that he generalized Frege's argument for the notion of sense so as to bypass his incorrect particularization to the case of identity.
\end{abstract}

This essay has the same title as the talk I gave in Kirchberg, but its scope is more limited. I began that talk by remarking that the technical notion of a symbol played in the Tractatus an analogous role to the one that conceptual content had played in Begriffsschrift and sense in Frege's later semantics, namely that of singling out the part of the content of a sign that is relevant to logic. I intended this remark as little more than throat-clearing - an uncontroversial observation that would help my audience to situate the argument I then went on to lay out-but during the question period it was met with consternation. I therefore think it best to devote my written contribution to explaining what I meant by the remark, since until I do that no one is likely to be convinced by an argument that treats it as an obvious background assumption.

\section{$1 \quad$ Begriffsschrift}

In the first few sections of Begriffsschrift Frege made several important logical distinctions. Right at the beginning, for example, he distinguished between a judgment and its content. He was not, of course, the first philosopher to make this distinction, but he was, as far as I know, the first to do it for the reasondubbed the 'Frege point' by Geach [4] - that it is required to explain how in the course of a logical argument a single content may occur unasserted and asserted in different occurrences. Even so, to make such a distinction between judgment 
and content is not yet to say anything illuminating about the nature of the latter. An important step - arguably the most important in all his philosophy of logic - came when he singled out what he called conceptual content - the part of content that is relevant to inference. Two sentences have the same conceptual content just in case the same inferences may be drawn from each. He called the conceptual content of a declarative sentence a 'judgable content'. The part of the content that this notion of conceptual content excludes he variously called 'colouring' (Farbung), 'illumination' (Beleuchtung), or 'scent' (Duft); in English Dummett [1] called it 'tone'. In Begriffsschrift Frege instanced 'and' and 'but' as words differing only in tone, not conceptual content; elsewhere he cited various other examples, such as 'horse' and 'steed', or 'dog' and 'cur'. The fact that he never settled on a single word for tone is symptomatic of his lack of interest in it: he only ever mentioned it in order to set it aside as irrelevant to logic.

The importance of this distinction is that it enabled Frege to make prominent those features of the structure of sentences that are relevant to inference. It is part of the logician's task, as of the grammarian's, to study how sentences reveal the structure of the contents they express, but their differing interests lead to different conceptions of that structure. The two sentences 'The Greeks defeated the Persians at Plataea' and 'The Persians were defeated by the Greeks at Plataea' have the same conceptual content, because the same consequences may be derived from each, whereas grammar quite properly distinguishes between the active voice of the verb in the former and the passive voice in the latter. The notion of tone is thus applicable not only to the contents of individual words but to the manner in which they are assembled to form sentences: sentences with the same conceptual content may differ in emphasis, and hence in tone, by having different terms as their grammatical subjects.

As is familiar, Frege later realized that his Begriffsschrift notion of conceptual content was inadequate and should be replaced. The important point to note here is that the notion he replaced it with, 'sense', was still intended to play the role of constituting the part of content that is relevant to logic. Unfortunately, though, this point is obscured by a significant oddity in the way 'On sense and reference' is written, namely that he chose hardly to mention formal logic there at all. Why not? The only reason I can think of is that he was continuing, as he had in Grundlagen to separate the formal from the philosophical in order to increase the chances of being read. At any rate, he deliberately emphasized the non-mathematical applications of his semantic theory and therefore obscured the point that his notion of sense was primarily a contribution to the philosophy of logic, not of language. It is uncontentious that there is some difference in content between 'Hesperus' and 'Phosphorus': what is at issue in 'On sense and reference' is whether logic should recognize it.

\section{Russell}

I have stressed the importance of the notion of conceptual content or sense for Frege's philosophy of logic. To see how important it was, we have only to look 
to the salutary example of Russell. He learned his quantificational logic from Peano, not Frege, and his first reaction to $\phi x_{x} \psi x$ (what we would now write as $\forall x(\phi x \rightarrow \psi x))$ was that this was plainly a different proposition from 'every $\phi$ is a $\psi$. He took it to be obvious that the former says something about everything there is (namely that it is either a $\psi$ or not a $\phi$ ), whereas the latter only says something about $\phi \mathrm{s}[8, \S 41]$. This is an instance - the Principles has many others scattered through it - of his failure to grasp Frege's insight that logicians should ignore the part of content that is irrelevant to inference. The result was that Russell kept treating as logical what were really only grammatical distinctions, and hence devising theories of hopelessly unnecessary complexity.

Not until the autumn of 1902, with the main text of the Principles complete, did Russell settle down to study Frege's published papers and write an appendix to his book that summarized them. Over the next two or three years the influence of his reading of Frege was occasionally visible in his own work. For instance, one feature of his 1905 paper that often goes unnoticed is the extent to which Russell's famous theory of descriptions depends on accepting something like the Fregean conception. It is one of the curiosities of 'On denoting' that it slips in this crucial step in a footnote, where, somewhat oddly, Russell attributes it to Bradley [7, p. 481]. The importance of focussing on the part of content that is relevant to inference is not the only thing in 'On denoting' that might have a Fregean source. The other central concern of the paper is the relevance of scope in explaining ambiguities. Thus, for instance, Russell used different possible scopes of the quantifier to explain he difference between de re and de dicto understandings of 'George IV wished to know whether Scott was the author of Waverley'. (Frege's influence on Russell evidently waned after 1905. When he re-explained his theory of descriptions later, in the Introduction to Principia, he did not use scope distinctions to motivate it.)

After 1911 he came under Wittgenstein's influence and became suspicious of his platonistic conception of logic as having a subject matter consisting of entities such as disjunction or negation. From the autumn of 1913 onwards, therefore, he used 'proposition' to mean the sentence, rather than what the sentence expresses. In his post-war work these linguistic items were the subject matter of logic, with the result that his conception of the subject became somewhat psychologistic.

\section{$3 \quad$ Early Wittgenstein}

Whereas Frege proposed a 'one-kind, two-step' semantics for singular terms, Russell's was a 'two-kind, one-step' theory, i.e. one that distinguished two kinds of singular term, definite descriptions and logically proper names, and proposed that the latter referred directly without any need for a third-realm intermediary. It may well be that Wittgenstein at first shared Russell's one-step conception, and hence rejected the need for Frege's distinction between sense and reference. In support of this one might quote a letter Jourdain wrote to Frege in January 1914. Jourdain at that time lived on the outskirts of Cambridge and had got 
to know Wittgenstein through Russell. (For a time it was proposed that he and Wittgenstein would collaborate on a translation into English of some parts of Frege's writings, but this did not occur, presumably because of the war: when this translation eventually appeared in 1915-17 Jourdain's collaborator was named as Johann Stachelroth.) Jourdain wrote to ask Frege, inter alia, 'whether, in view of what seems to be a fact, namely, that Russell has shown that propositions can be analyzed into a form which only assumes that a name has a 'Bedeutung', \& and not a 'Sinn', you would hold that 'Sinn' was merely a psychological property of a name' [3, p. 78]. Perhaps Wittgenstein was behind Jourdain's question. If so, then at this time (or, at any rate, when he departed for Norway the previous October) Wittgenstein still sided with Russell against Frege's sense/reference distinction.

At that time, though, Wittgenstein still hoped to devise a 'logically perfect' notation which would make the logical properties of a sign transparent. By the time of the Moore dictation in April 1914, however, his search for such a notation had stalled. He therefore began instead to stress the importance of seeing past the 'particular scratches' to the symbolism's 'logical properties' $[9$, p. 112]. Nonetheless, with no label for the distinction he was compelled to speak opaquely of 'seeing the sign in the sign' [9, 23 Oct. 1914]. Not until he had reached page 54 of the Prototractatus volume did he introduce a separate word for what it is that we are supposed to see. Even then, his immediate purpose in doing so was only to make a point about the ambiguity of ordinary language, namely that one sign might represent different symbols in different occurrences. Not until later, it seems, did he realize that even if he had, per impossibile, found a logically perfect notation, there would still have been a role for the distinction.

\section{$4 \quad$ Sign and symbol}

In the Tractatus the distinction between sign and symbol is introduced via that between propositional sign and proposition, and this in turn emerges as a consequence of features of the picture theory of meaning. A picture, according to that theory, is a fact that shares its form with the part of reality that it attempts to represent. A proposition is a picture with two extra features: first, its form of depiction is logical; second, it is 'expressed perceptibly through the senses' $[10,3.1]$. These two features then give rise to the need for a distinction between the proposition the propositional sign through which it is expressed, since otherwise the picture theory would hold, absurdly, that we can read off the structure of the world from the structure of the signs we use to represent it.

One might be tempted to think that by 'propositional sign' Wittgenstein just meant 'sentence', except that this word, like 'picture', in ordinary usage means a complex, whereas Wittgenstein was explicit [10, 3.14] that a propositional sign is a fact, i.e. it is already parsed so that its grammatical structure is revealed. So a propositional sign and a proposition are both facts, but their forms are different: perceptible in the former case; purely logical in the latter. It is this 
difference in form that explains why we cannot simply read off the structure of the world from that of language. Propositions, according to the Tractatus, share their form with the parts of the world they represent; propositional signs do not.

Having thus distinguished between propositional sign and proposition, Wittgenstein distinguished analogously between their meaningful constituents, which he called signs and symbols (or expressions) respectively. (The qualifier 'meaningful' is needed here to rule out treating 'es is mor', for instance, as a sign because it occurs in 'Socrates is mortal'.) 'What is essential in a symbol,' Wittgenstein said in the Tractatus, 'is what all symbols that can serve the same purpose have in common.' [10, 3.341] In the notes dictated to Moore he was slightly more explicit about what kind of 'purpose' he had in mind. 'What symbolizes in a symbol,' he there wrote, 'is that which is common to all the symbols which could in accordance with the rules of logic ... be substituted for it.' [9, p. 117]

We have now arrived at the sense in which Wittgenstein's notion of a symbol in the Tractatus is analogous to that of conceptual content in Begriffsschrift and sense in Grundgesetze. Wittgenstein, like Frege, wanted to focus attention on the features of a word's content that contributes to its logical role. 'Seeing the symbol in the sign' consists in seeing past the contingent properties of a sign to these features.

It can never indicate the common characteristic of two objects that we symbolize them with the same signs but by different methods of symbolizing. For the sign is arbitrary. We could therefore equally well choose two different signs and where then would be what was common in the symbolization? [10, 3.322]

To say that Tractarian symbols play broadly the same role as Fregean senses is not to say that they are identical, though. Frege's idea was that conceptual content or sense is inferential power. The difficulty comes in how we cash this out. If sentences have the same conceptual content only when they have the same immediately derivable consequences, then the notion becomes too sensitive to which consequences we take to be immediate. You may find obvious an inferential step that for me requires explanation, in which case this notion has no place in an account of logic that aspires, as Frege's did, to be independent of psychology. Once a formal system is in place, there will of course be an objective criterion for the immediacy or otherwise of a deduction, but this will depend on the system chosen and hence be unsuitable to serve, as he intended his notion of conceptual content to serve, as part of the grounding for that very system. Wittgenstein accused Frege of having wrongly imported psychological considerations into logic. 'It is remarkable,' he complained, 'that so exact a thinker as Frege should have appealed to the degree of self-evidence as the criterion of a logical proposition.' [10, 6.1271] This is an instance, I think, of Wittgenstein's repeated tendency to take hold of an idea and apply it more resolutely than its originator. Here he resolutely ignored psychological considerations of obviousness, so that what the individual reasoner is irrelevant to 'seeing the symbol in 
the sign'; all that matters is what is said about the world. In particular, then, logically equivalent propositional signs express the same proposition.

\section{Ramsey}

Wittgenstein famously had a copy of the typescript in his possession at the armistice, and it was this copy that he sent to Keynes in 1919 for onward delivery to Russell. Russell left this copy with Wrinch when he departed for China, and she eventually managed to get Ostwald to publish it as an issue of his monograph series. An advance proof copy of this version of the book reached Ogden in Cambridge at the beginning of November 1921 (letter to Russell, 5 Nov. 1921). It was presumably this copy that Ogden lent to Ramsey (then a second year undergraduate) shortly thereafter and which, as his father later recalled, 'interested him greatly'.

These details of just when Ramsey first read the book lend an intriguing aspect to the earliest of his philosophical essays to have survived, namely a talk on the nature of propositions that he delivered to the Cambridge Moral Sciences Club at the end of that November. There he proposed a multiple relation theory of judgment which, although certainly not the same as the one in the Tractatus, is at least similar in broad outline. What is clear, at least, is that his interest in the Tractatus made him an obvious choice as translator. According to his father's memoir he dictated his draft at Miss Pate's typing office in Trinity Street Cambridge in March 1922. The story of how Ogden sent the resulting typescript to Wittgenstein in Trattenbach to correct is now well known.

The book finally appeared in the dual-language edition in the autumn of 1922. Moore (who had been responsible for suggesting the Latin title by which the English version is known) was by then Editor of Mind and commissioned a critical notice of the book from Ramsey. He wrote this in August 1923, just after graduating at Cambridge as what was then called a ' $\mathrm{B} *$ Wrangler' in the Mathematical Tripos. (This meant that he got a First in Part A and a Distinction in Part B of his final exam.) Ramsey's critical notice was the first serious contribution to the secondary literature on the Tractatus, and it remains one of the best. For our purposes here what is relevant is an exegetical suggestion he made there. From what was said above we might well be puzzled about the nature of Tractarian symbols. To help us understand the idea, Ramsey proposed to make use of Peirce's terminology of type and token. This is now standard, of course, but when Peirce proposed it in 1906, few others took much notice. Two who did were Ogden and Richards, who quoted the relevant passage of Peirce in their book, The Meaning of Meaning [5, pp. 433-4]. Ramsey then adopted this terminology. Sign and symbol, he suggested, are not token and type - a sign is already a type, as Wittgenstein's gnomic observation that " $\mathrm{A}$ " is the same sign as "A"' [10, 3.203] was intended to make clear-but rather two ways of typing the tokens, whether according to syntactic properties (signs) or logical role (symbols).

On the face of it, Ramsey's way of putting the matter discourages us from 
hypostasizing symbols as occupants of a Fregean 'third realm' intermediate between language and reality. However, there are two points that tell against such a deflationary view. First, as Ramsey also later noted (after he had discussed the Tractatus with its author, it should be said), there may well be some types of which there are no token instances. 'It cannot be any concern of ours,' he said, 'whether anyone has actually symbolized' it [6, p. 33]. Whether we want to say that a type with no tokens inhabits an abstract 'realm' is perhaps a relatively minor matter. Second, the transition from a propositional sign to a proposition is not quite as straightforward as Ramsey's exegesis suggests. It is not merely a matter of grouping different signs together, but of changing the form of the fact. The form of the propositional sign might be spatial (if it is written) or temporal (if it is spoken), whereas the form of the proposition is purely logical. So it cannot be said that Ramsey has altogether demythologized the transition.

\section{Identity}

Wittgenstein used the sign '=' (much as Frege had used ' $\equiv$ ' in Begriffsschrift), to stand between signs that express the same symbol. In particular, as he explained in the Prototractatus [11, 4.2213], he used it between propositional signs that express the same proposition. Oddly, though, he dropped this explanation from the final version of the book, despite continuing there to use it in this way (e.g. 4.0621, 5.51, 5.52). This similarity between the Tractatus and Begriffsschrift uses of the equality sign invites an obvious question, though. In 'On sense and reference' Frege rejected the Begriffsschrift account of identity. So why does this objection not also apply to Wittgenstein's account in the Tractatus? Frege's objection was in effect that his previous account had made identities metalinguistic. (He did not use that word, of course, which did not become current until the 1930s.) In the Tractatus Wittgenstein simply accepted this. On his account '=' is a sign of the metalanguage, not the object language.

What, though, of Frege's objection that identity sentences do sometimes express non-trivial information? Frege's central idea was that we need the notion of sense in order to allow for the fact that the objects we refer to may have other aspects of which we are currently unaware, and yet that does not prevent us from referring to them successfully. In his draft reply to tbe letter from Jourdain quoted earlier, Frege made this point by using the example of a mountain seen from different directions by two explorers, one of whom names it 'Aphla', the other 'Ateb'.

What is striking here is surely the sense of two philosophers taking past each other. Frege's example of Aphla and Ateb certainly would not have impressed Russell, who would have said that 'Aphla' and 'Ateb' are not logically proper names but disguised descriptions. The place where this point surfaces in the Tractatus is in Wittgenstein's stipulation that in the formal language we have no need of a sign of identity, because we can just agree never to refer to the same object with two different simple signs. Frege's point had been that this stipulation is impossible to implement, because there are cases in which we do 
not yet know that the two signs do refer to the same thing. Wittgenstein's response was that when it comes to Tractarian objects, we do always know: a Tractarian object, unlike Frege's mountain, is not the kind of thing that can have other, as yet unknown aspects to it.

I suggested earlier that it was a feature of Wittgenstein's way of thinking to press an idea more resolutely than its originator had done. Here we have another instance of this. In 1914 Frege still conceived of his sense/reference distinction, as he had when he introduced it in the 1890 s, as motivated narrowly by a point concerning identity. In this, though, he was mistaken. To see why, we need only notice the difference in inferential power, on Frege's conception, between 'Hesperus is a planet' and 'Phosphorus is a planet'. This difference suffices to show that 'Hesperus' and 'Phosphorus' have different senses, but does not mention identity at all. This suffices to show that Frege had mislocated the point of the distinction. Frege thought that the distinction between sense and reference was needed so as to leave room for objects to have unknown aspects. On Wittgenstein's view, the distinction is needed in order to leave room, more generally, for the structure of our signs to differ from that of the world.

\section{References}

[1] Dummett, M., Frege: Philosophy of Language (Duckworth, 1973)

[2] Frege, G., Begriffsschrift (Halle: Nebert, 1879)

[3] Frege, G., Philosophical and Mathematical Correspondence (Oxford, Blackwell: 1980)

[4] Geach, P. T., 'Assertion', Phil. Review, 74 (1965), 449-65

[5] Ogden, C. K. and Richard, I. A., The Meaning of Meaning (Kegan Paul, Trench, Trubner \& Co, 1923)

[6] Ramsey, F. P., Foundations of Mathematics, and other essays (Kegan Paul, Trench, Trubner \& Co, 1931)

[7] Russell, B., 'On denoting', Mind, 14 (1905), 479-93

[8] Russell, B., The Principles of Mathematics (Cambridge University Press, 1903)

[9] Wittgenstein, L., Notebooks 1914-1916, ed. by G. H. von Wright and G. E. M. Anscombe (Oxford: Blackwell, 1961)

[10] Wittgenstein, L., Tractatus Logico-Philosophicus (Kegan Paul, Trench, Trubner \& Co, 1922)

[11] Wittgenstein, L., Prototractatus, ed. by B. F. McGuiness, T. Nyberg and G. H. von Wright (Routledge, 1971) 